\title{
A STUDY ON RING PACK LUBRICATION IN INTERNAL COMBUSTION ENGINE
}

\author{
I. B. Mshoro \\ University of Dar es Salaam, Department of Mechanical Engineering \\ P.O. Box 35131, Dar es Salaam. Tanzania
}

\section{ABSTRACT}

Most of the lubricating oil from Internal Combustion Engine (ICE) is lost through piston rings. Hence, in order to optimally reduce ICE oil consumption, a better insight into the tribology of the ring pack is required. This can only be achieved by an improved characterization of the lubricant behaviour within the operating environment of the engine. In the present work, an optical technique using laserinduced fluorescence was employed to measure oil film thickness within the ring pack. The experiment was conducted on a Phaser 1000 Series engine, whereby optical access to the ring pack was achieved by a fused silica-window positioned flush with the inside surface of the liner. It has been observed that for a given engine operating condition there are significant cyclic variations in oil film thickness. For example, for an engine torque of $200 \mathrm{Nm}$ at $1250 \mathrm{revs} / \mathrm{min}$, oil film thickness around the top ring varied by up to $230 \%$ between two consecutive strokes. The same trend was obsened for all other rings whereby compression rings were lubricated by a thicker film during expansion and intake strokes than during compression and exhaust, whilst it was the opposite for the oil control ring. Furthermore, oil film thickness under compression rings was observed to be virtually unaffected by increasing engine speed and load. On the other hand, lower engine speeds and torque yielded thicker lubrication films on the oil control ring, inrespect of the fact that the lubrication regime was hydrodynamic. This is explained by the decrease in oil viscosity due to the observed increase in oil temperature within the ring pack as engine speed was increased. Generally, the largest net oil flows occurred during the power cycle to indicate the dominance of the scrapping action of the second compression and the oil control rings. Although the results of this study have shed some new lights in the understanding of lubricant behaviour within the ring pack under operating environment of the engine, more work is still required to improve the in-situ calibration adopted in this experiment to relate the fluorescence intensity and oii film thickness. While it was anticipated that the grooves in the calibration cell will be completely filled with oil, the same did not happen all the time as the filling of grooves was stochastic in nature to call 
Mshoro

for numerous preliminary attempts before any reliable measurements could be made.

\section{INTRODUCTION}

Considering the high rating of modern ICE, optimization of their tribological performance is becoming an increasing concern for engine developers worldwide. Current practice in this direction is dictated by the requirement to improve fuel economy of ICE while simultaneously meeting emission legislation and smooth running with longer intervals between oil changes. In order to meet the latter demand, reduction in oil consumption is targeted at $0.2 \mathrm{~g} / \mathrm{kWh}$ for ICE intended for medium and heavy duty automotive applications. Since about $75 \%$ of engine's oil consumption is due to losses through the ring pack, different researchers have proposed various approaches for reduction of oil while avoiding significant wear of engine components. Wacker and Coelingh ${ }^{11 \prime}$ suggested that the top ring land should be at a height of about $10 \%$ of the cylinder bore diameter, with a constant small clearance between the piston and cylinder. This design was said to offer the required optimum reduction in oil consumption due to greater piston skirt guidance length. Wakuri et. $\mathrm{al}^{121}$ adopted a similar method and observed that cylinder polishing could also be prevented due to increased pision guidance, by controlling the build-up of carbon deposits on the top ring land. In this implementation, carbon deposited on the top ring land was constantly removed at the change of contact with the cylinder at Top Dead Centre (TDC), while avoiding contact in cylinder areas covered by the ring pack. In further development by Parker et. $\mathrm{al}^{\mid 34}$, it was proposed to employ the so-called inter-ring pressure balancing, whereby a larger ring gap is provided for the second compression ring in conjunction with a large clearance between the top ring land and the cylinder. Alternatively for the same purpose, an enlarged crevice volume at the top ring land was combined with an increased first inter-ring gap. In both cases pressure balancing was achieved since for most of the engine cycle the top and second piston rings stayed at the bottom faces of their grooves while the oil control ring remained in contact with the upper face of its groove.

However, all the above measures in the reduction of oil consumption were development-oriented and could not characterize the ring pack oil film behaviour in a manner sufficient to assist in the understanding of the actual phenomenon. A better insight into the tribology of ring pack can only be achieved by an improved characterization of the lubricant behaviour within the operating environment of a ring pack. Current theoretical models of piston ring operation are very sophisticated and undoubtedly produce good qualitative results ${ }^{[4]}$. However, it must be 
emphasized that the results are generated from theoretical bases, which inherently employ simplifying assumptions. In some attempts to realistically monitor oil film around the ring pack under engine operating environment, many experimental techniques have been employed with various levels of success. Sherrington and Smith ${ }^{|!| ! \mid}$, and Grice et. al ${ }^{1111}$ investigated ring pack oil film trends, film stability and cavitation using a capacitance based system. However the accuracy of this method was not satisfactory due to the limited range of capacitive transducers. In an effort to improve the accuracy, Grice and Sherringdon ${ }^{\mid 12]}$ measured ring pack oil film thickness using two complementary techniques based on capacitance and inductance transducers. This technique could also not yield satisfactory results calling for a further refinement of the inductive measurement to reduce the remnant contribution of the carrier signal and permit higher operating sensitivity over a wider range. The observed inaccuracy in the results was attributable to the difficulty of accessing the working environment of the ring pack in a genuinely non-invasive manner. In order to avoid the above shortcoming several researchers have employed optical techniques using laser-induced fluorescence to measure oil film thickness between a fixed point on cylinder-liner and piston. Among the earliest studies were those by Greene $^{[1.31}$ who made qualitative observations of a flourescently-doped oil between a motored piston and a transparent liner using a high-speed cine photography. Ting ${ }^{141}$ improved the technique by focussing a laser radiation onto the cylinder liner so that all the piston rings passed the interrogation spot around the mid-stroke. By monitoring the variations in flourescence intensity during the engine cycle qualitative information about oil film thickness in the laser beam's focal volume could be obtained. However, the principle problem encountered in this technique has been quantifying the relationship between the flourescence intensity and the actual oil film thickness in the piston/liner contact. This requires a calibration procedure, which relates the intensities to a known oil film thickness.

Hoult et. al ${ }^{115 \mid}$, Hoult and Takiguchl ${ }^{161}$ and Wong et. $\mathrm{al}^{71}$ have suggested several strategies for calibrating oil florescence measurements that have been made in an operating engine through a window mounted onto the cylinder liner. The accuracy of results seemed to improve in all these works although could not be enhanced to the expected level due to the observed fluorescence quenching effects. Fluorescence quenching was attributed to the temperature dependence of the fluorescence intensity due to collissional relaxation processes which were observed to deplete the electronically excited states responsible for the fluorescent emission. These quenching processes are enhanced as the temperature of oil sample rises. Hence, it implies that the temperature of the oil film at the measurement point must 
be known if accurate film thicknesses were to be determined in conjunction with the adopted calibration procedure. In all the mentioned works temperature was not monitored

In the present work, an optical technique using laser-induced fluorescence will be employed to measure oil film thickness within the ring pack. In order to overcome the problems of fluorescence quenching as observed by previous researchers, oil film temperature was simultaneously measured. Furthermore, the author used in-situ calibration by introducing grooves of known depth in the piston skirt and top compression ring. It is anticipated that the grooves will be completely filled with oil and any changes in the flourescence characteristics emitted by the groove sample will be a consequence of changes in the conditions experienced by the oil.

\section{EXPERIMENTAL MATERIALS AND METHOD}

The experiment was conducted using a four stroke-six cylinder direct injection diesel engine with the specifications as presented in Table 1. Measurements were taken from Cylinder No 1 whereby optical access to the ring pack was achieved by machining the block and the liner such that a fused silica window held in a suitable mount could be positioiied flush with the inside surface of the liner, to avoid obstruction. The window was located at Bottom Dead Centre (BDC) in the direction of gudgeon pin. For the given piston length and engine speed $(168 \mathrm{~mm}$ and 2500 revs/min respectively), it will take $45 \circ$ of crankshaft rotation for the whole piston to pass through the optical window each stroke. Hence, oil film thickness over the piston (which includes ring pack) will be monitored for $180^{\circ}$ of crankshaft rotation per engine cycle. For a particular ring, oil film thickness will be monitored once each stroke, within the relevant $45^{\circ}$ of crankshaft rotation - in proportion to ring width (Table 1). Mean cyclic variation of oil film thickness on

a ring is then obtained by numerical interpolation of instantaneous results from four strokes per cycle, with subsequent averaging of data from 275 consecutive cycles. In order to obtain the oil film thickness between the cylinder and piston at a given torque and speed it was required to simultaneously measure the flouresence intensity and temperature of the oil film.

The experimental set-up is schematically illustrated in Fig. 1. The flourescence excitation light was obtained from Argon-Ion laser type 5490AWC and purified with a narrow bandpass interference filter to remove the residual plasma emission from the beam. The laser radiation was then steered through the optical window using a conventional mirror and latter through a dichronic mirror with multilayer 
A study on ring pack lubrication ...

Table 1: Test Engine Specifications

\begin{tabular}{||l|l||}
\hline Engine type & Phaser 1000 \\
\hline Rated power, $[\mathrm{KW}]$ & 156 \\
\hline Rated speed, $[\mathrm{rev} / \mathrm{min}]$ & 2500 \\
\hline Cylinder diameter, $[\mathrm{mm}]$ & 100 \\
\hline Engine stroke, $[\mathrm{mm}]$ & 127 \\
\hline Number of rings per piston & 3 \\
\hline Top ring (compression) width, $[\mathrm{mm}]$ & 3.1 \\
\hline Second compression ring width, $[\mathrm{mm}]$ & 2.5 \\
\hline Width of oil control ring (top rail), $[\mathrm{mm}]$ & 6.5 \\
\hline Width of oil control ring (bottom rail), $[\mathrm{mm}]$ & 1.1 \\
\hline Position of optical window from TDC, $[\mathrm{mm}]$ & 127 \\
\hline Type of engine oil & $\mathrm{SAE} 40$ \\
\hline
\end{tabular}

dielectric coatings. The mirror was set at $45 \circ$ incidence to ensure maximum reflection. In order to characterize the oil film associated with the passage of piston ring, the fluorescence signal was sampled with a spatial resolution commensurate with the maximum temporal resolution of the analogue-to-digital converter in the Data Collection Equipment. This required the laser beam to be weakly focussed to a beam width of approximately $150 \mu \mathrm{m}$ using a plano-convex fused lens positioned in the optical path just before the dichronic mirror as shown in Fig. 1.

The flourescence signal was collected and imaged using a high aperture, refractortype Long Working-distance Microscope LWM Model K2. The standard objective a working distance between $500 \mathrm{~mm}$ to $2.3 \mathrm{~m}$, with magnifications of 1.2 and 0.25 lens of the K2 is specifically designed to piovide a continuous focussing range from respectively. The image formed in the conjugate plane of the objective lens was magnified ten times using a conventional microscope ocular and the light intensity was then detected by a photo-multiplier tube (EMI 9202B). The output current 


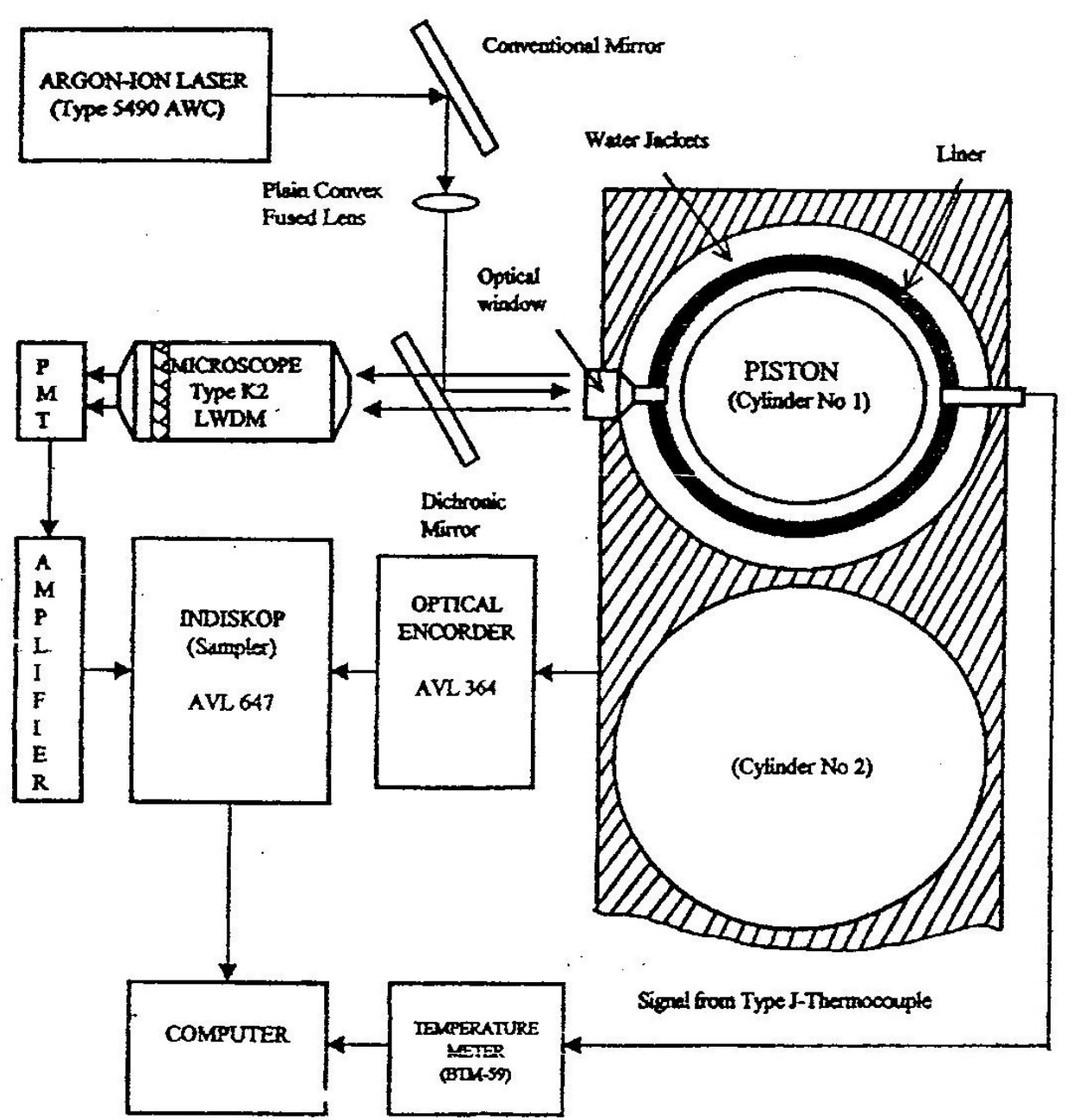

Fig. 1: Schematic illustration of experimental set up

from the phototube was dropped across a load resistance of $100 \mathrm{k} \Omega$ and amplified by a variable gain amplifier Type FE-351UA so as to provide a voltage signal of suitable frequency response and magnitude for subsequent signal sampling. For this, an AVL 647 Indiskop capable of sampling at rates of up to $250 \mathrm{kHz}$ was used. Its data acquisition system that sampled with 12-bit resolution once every $0.1 \circ$ crankshaft rotation was driven externally by an optical encoder (AVL 364) attached to the crankshaft pulley.

The relationship between the flourescence intensity and the actual oil film thickness in the ring pack and piston/liner contact was obtained via a calibration procedure, which relates the intensities to a known oil film thickness. For this purpose, in-situ calibration cell was made which was in the form of grooves of $30-35 \mu \mathrm{m}$ depth made by spark erosion in the piston skirt and top compression ring. Since the grooves vere to he completely filled with oil then any changes in the flourescence 
characteristics cmitted by the groove oil samples will be a consequence of changes in the conditions experienced by the oil via an empirical expression,

$$
F_{c}=k_{t} . \delta_{c}+F_{i}
$$

where.

$F_{\text {- }}$ - current flourescence intensity;

$k_{t}$ - temperature dependent calibration coefficient;

$\delta_{c}$ - current oil film thickness;

$F_{i}$ - initial flourescence intensity.

From Eq. (1) it is clear that the temperature of the oil film at the measurement point must be known if accurate film thicknesses are to be determined in conjunction with calibration procedure. The temperature dependent calibration coefficient $\left(k_{l}\right)$ was determined from appropriate nomographs based on the measured oil temperature. Oil film temperatures were measured using a fast response J-type coaxial thermocouples and the output signal was sent to a calibrated cold junction and amplifier. The thermocouples were mounted at the same vertical height as the window but on the opposite side of the liner in the direction of gudgeon pin. In order to obtain adequate representation of the film thickness as a function of engine cycle the fluorescence intensity had to be time-averaged over 275 consecutive engine cycles. At a selected engine condition (torque of $200 \mathrm{Nm}$ at $1250 \mathrm{revs} / \mathrm{min}$ with coolant temperature maintained at $90^{\circ} \mathrm{C}$ ), the repeatability between consecutive averages for 275 cycles was good for data collected over a 30 minute time scale.

\section{RESULTS AND DISCUSSION}

\section{Cyclic Variation of Minimum Oil Film Thickness within the Ring Pack}

Fig. 2 illustrates the variation of minimum oil film thickness associated with the passage of the ring pack past the measurement point during the engine cycle. It is observed that there are significant variations in oil film thicknesses within the engine cycle. For the top ring, for example, the oil film thickness increased by about $39 \%$ as the piston progressed from compression to expansion. Subsequently, the film thickness dropped by about $230 \%$ during the exhaust stroke before rising again by about $140 \%$ during intake. Qualitatively the same trend is also observed for all the other rings.

It is however important to note that the cyclic variation in oil film thicknesses follow different sequence between the compression and oil control rings. While the 


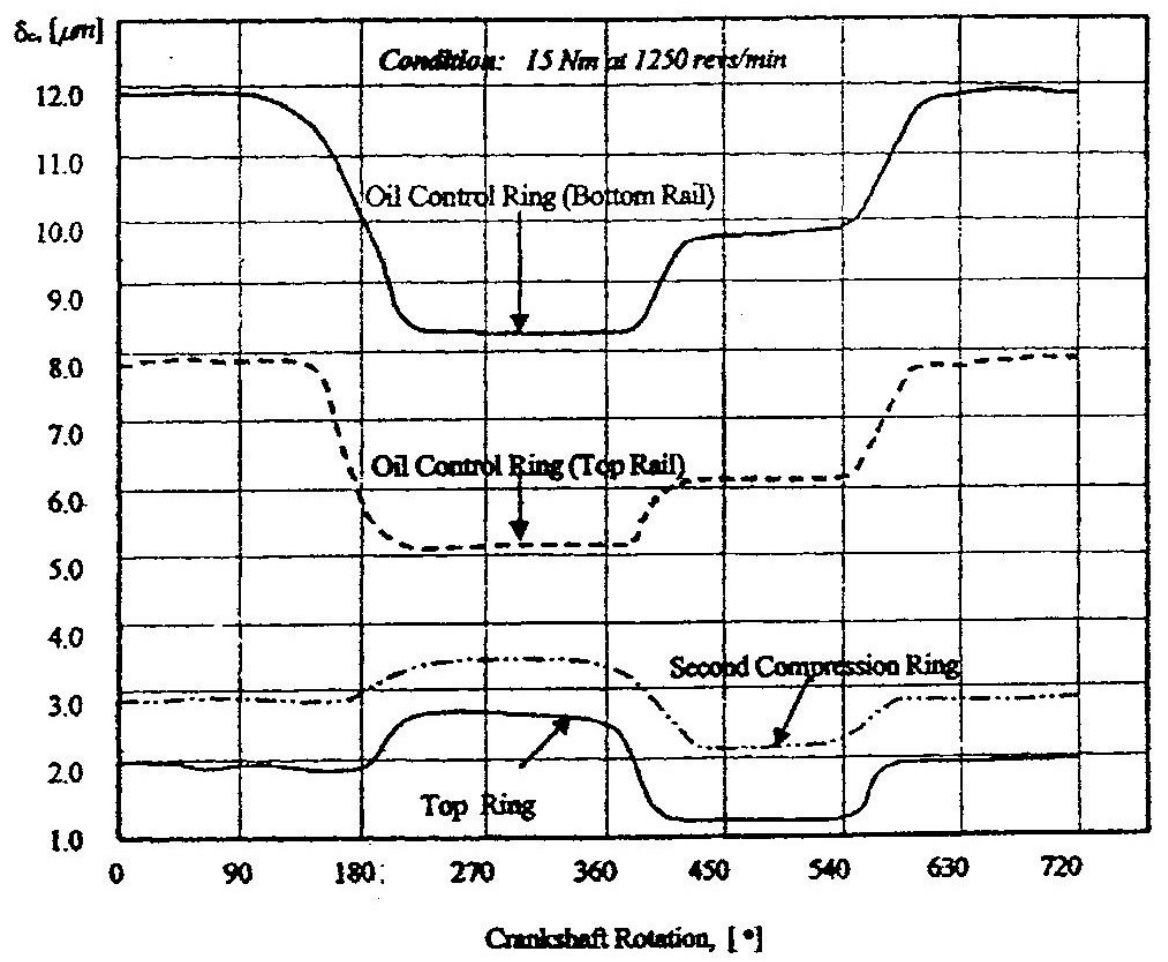

Fig. 2: Cyclic variation of oil film thickness under each piston ring

compression rings were observed to be lubricated by a thicker film during expansion and intake strokes than during the compression and exhaust, the sequence was opposite for both rails of the oil control ring. In terms of magnitude, it is observed that the oil film thickness decreases on progressing from the oil control ring (maximum thickness about $12 \mu \mathrm{m}$ ) through the ring pack to the top ring which is lubricated by oil with maximum film thickness at $2.5 \mu \mathrm{m}$.

From the observed results it is apparent that the dynamic action of the rings have a profound influence ov222er the oil film thickness behaviour. During compression and exhaust strokes the compression rings form the advancing edge of the ring pack and will be lubricated by the oil left behind on the liner at the end of the previous stroke. Under this condition the oil film on the lower reaches of the liner will be partially refreshed with oil dragged up by the piston skirt. The extent of replenishment will be limited by the extreme position of the oil control ring. On the down strokes (expansion and intake) the two rails of the oil control ring form the advancing edge of the ring pack and they essentially regulate the supply of oil to the remaining rings. Although this ring is under significant spring tension, the gas loading on the ring is minimal during the engine cycle. These factors coupled with the ample supply of oil from the liner ensure that the rails are supported 
hydrodynamically by a relatively thicker film. It is logical that the action of the oil control ring during the down strokes allows a thicker film to pass under its top rail than during the up strokes and hence more oil is made available for the subsequent lubrication of the compression rings. The cyclic variations in oil film thickness under the rails of the oil control ring is consistent with a flexing of the ring such that the advancing rail forms a better contact with the cylinder liner and thus allowing a more efficient scraping action.

\section{Effect of Engine Speed and Torque on Ring Pack Lubrication}

The influence of engine speed on oil film thickness within the ring pack is shown in Fig. 3. In the assessment of the effect of engine speed, a constant low output torque of about $20 \mathrm{Nm}$ was inaintained throughout the experiment.

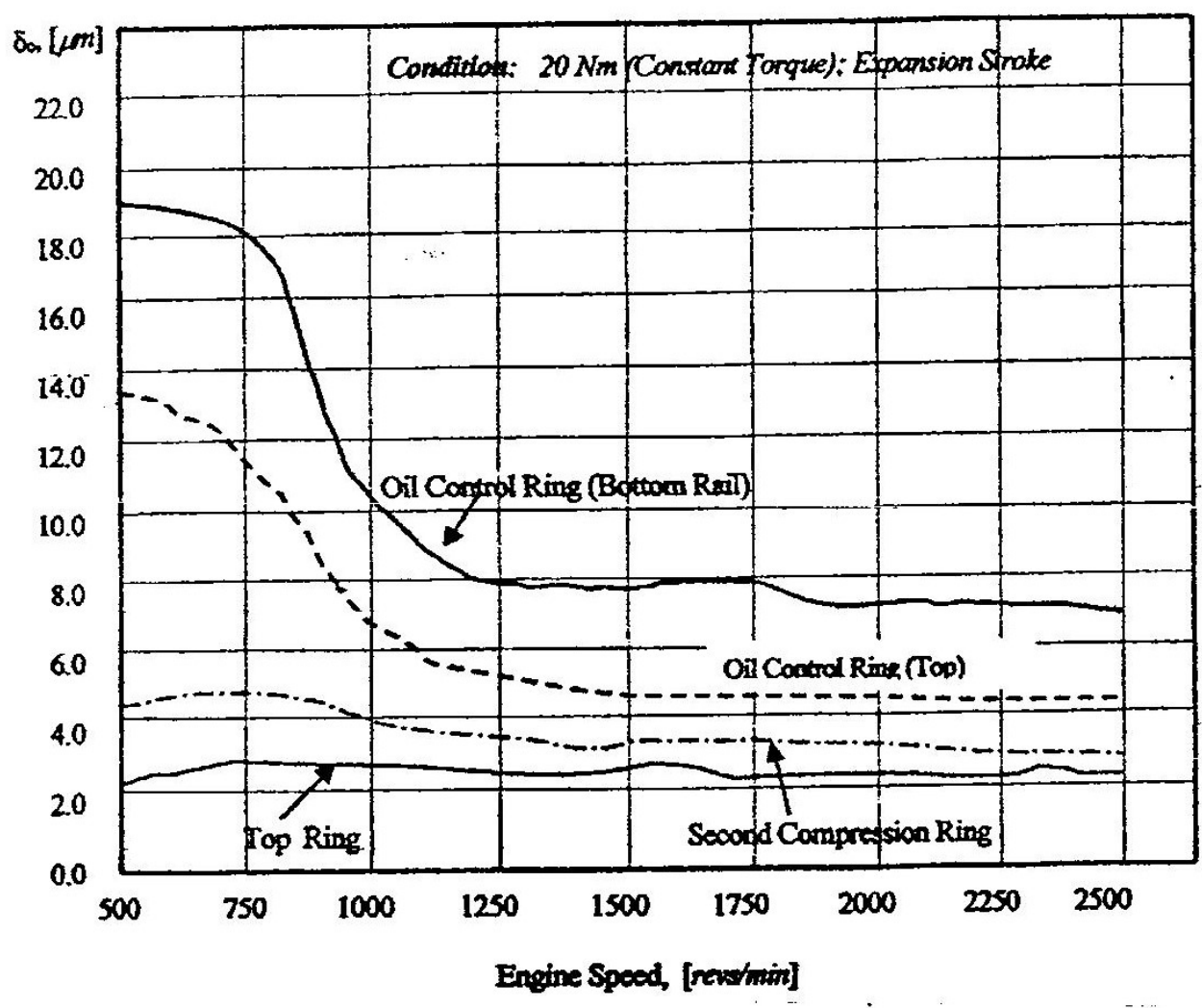

Fig. 3: Effect of engine speed on ring pack lubrication

It is observed that the oil film thickness under compression rings is virtually unaffected by increasing engine speed. On the other hand, lower engine speeds are observed to yield thicker lubrication films for both rails of the oil control ring. While for the compression rings the mean oil thickness was about $2.0 \mu m$ throughout the 


\section{Mshoro}

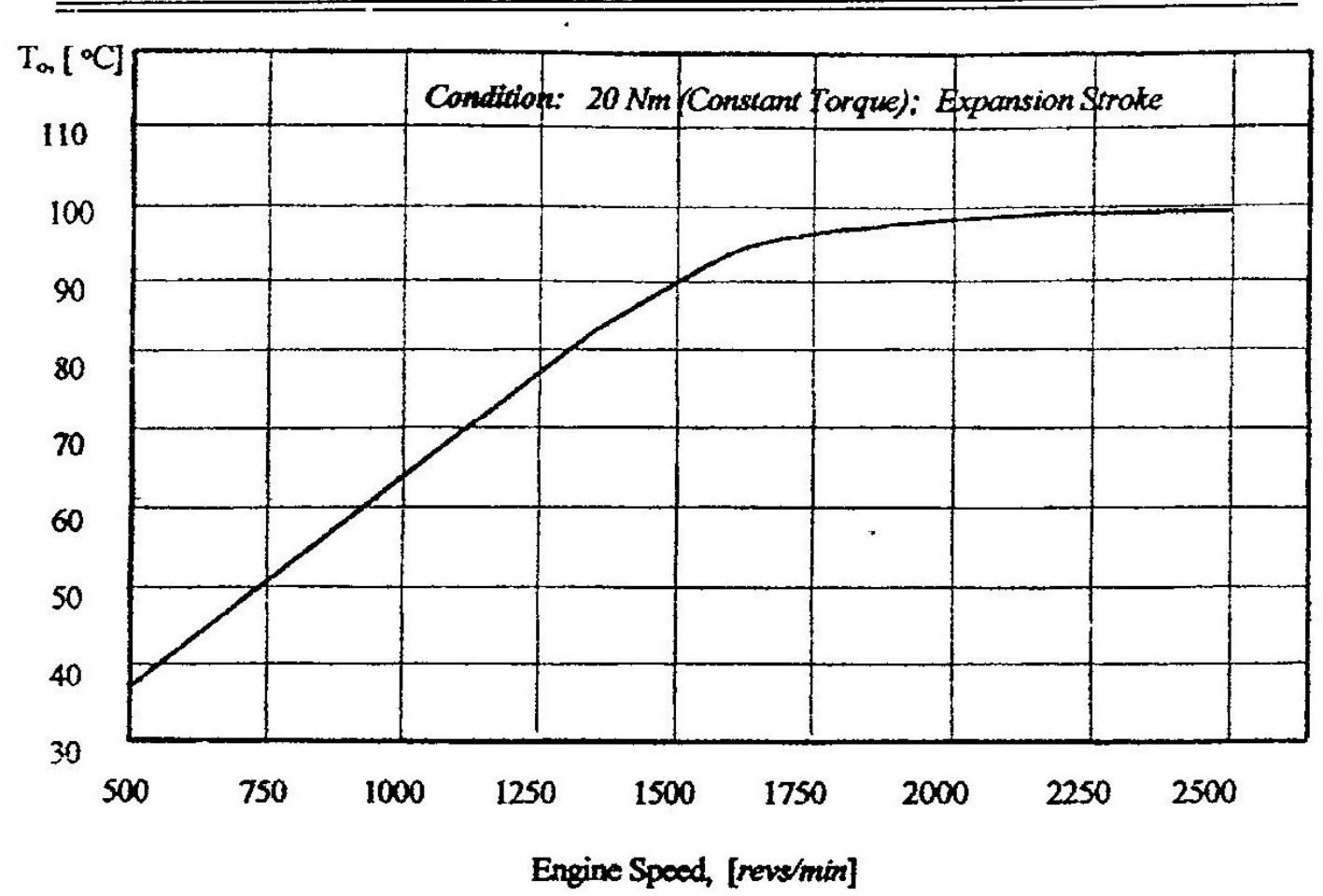

Fig. 4: Influence of engine speed on mean oil temperature

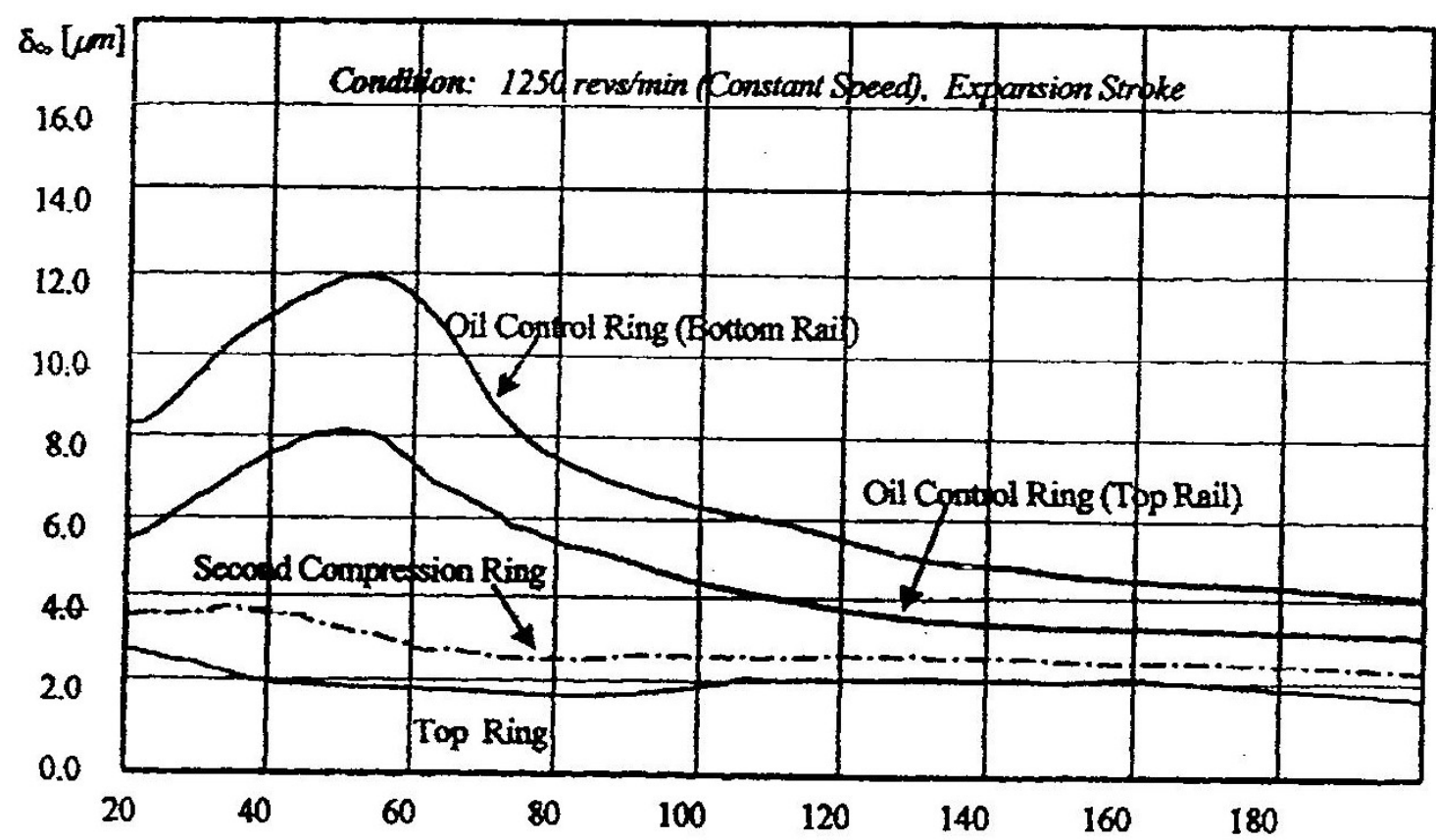

Engine Torque, $[\mathrm{Nm}]$

Fig. 5: Influence of engine torque on minimum oil thickness within the ring pack 
speed range tested, the oil control ring experienced a film of about $19.0 \mu \mathrm{m}$ at the lower extreme of speeds and $3.5 \mu \mathrm{m}$ at maximum speed. These experimental observations appear to deviate from basic theoretical expectations ${ }^{|18,19|}$ that if the ring lubrication regime is hydrodynamic then the film thickness under the rings should increase with engine speed. The above inconsistency is probably attributed to the observed increase in mean oil temperature $\left(T_{0}\right)$ within the ring pack as engine speed was increased (Fig. 4).

Based on a well known viscosity-dependency on temperature, the increase in oil film temperature with engine speed should consequently lead to the decrease in oil viscosity. Thus, even if the rings are lubricated hydrodynamically, the oil film thickness may not necessarily increase with engine speed as the theory predicts, but will depend on the specific mutual interaction of the contradicting effects of engine speed on oil flow rate and viscosity. Furthermore, there is an additional complexity in that the compression rings may in fact be running under boundary lubrication.

The effect of engine torque on oil film thickness at constant engine speed (1250 revs/min) is illustrated in Fig. 5. As it was the case for engine speed, the oil film thickness under both rails of the oil control ring is reduced with increased toryue. On the expansion stroke the amount of lubricant passing under the oil control ring appears to have a profound influence over the oil film thickness in the rest of the ring pack. The film thickness behaviour at low engine torque and speed is probably due to easier transport of lubricant which at such conditions will have relatively lower temperature and hence viscosity. Consequently, inherently large amount of oil will be available for supply to the cylinder liner and for subsequent transport through the ririg pack.

\section{Characterization of Oil Flow}

It has been observed from the results presented above that there are significant cyclic variations of oil film thicknesses within the ring pack. This suggests that if the oil volume between any region of the piston and the liner can be calculated then from the intra-stroke variation one can infer the magnitude and direction of the net oil flow. Hoult et. al ${ }^{\mid 15 !}$, Hoult and Takiguch $\mathrm{f}^{161}$ and later Wong et. $\mathrm{dl}^{71}$ have already performed such analyses. A similar approach is adopted here but with improved assumption that during the expansion stroke the apparent increase in oil film thickness after the piston passes the optical window is due to the detection of light emission from the combustion flame. 


\section{Mshoro}

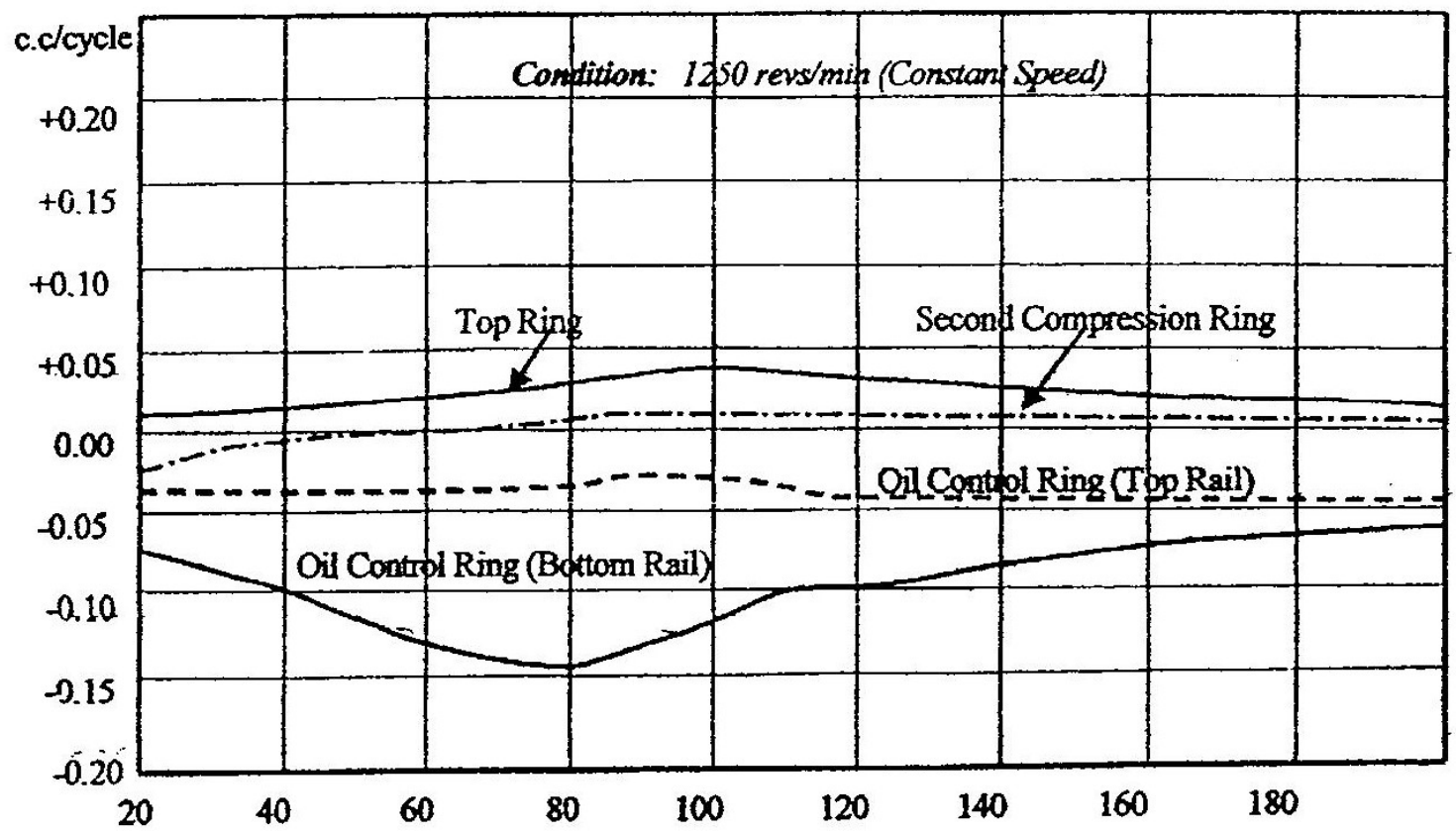

Engine Torque, [Nm]

Fig. 6: Net oil flow from individual rings during the power strokes

It is assumed that the combustion light dominates any contribution due to fluorescence from the residual oil film left behind on the window after the piston crown has passed. Thus, for a given portion of stroke the associated oil volume was estimated by integrating the area under the appropriate portion of the oil film thickness curve then multiplying the same by the liner circumference. Figs. 6 and 7 show the net oil volume change between strokes as determined with this method. It is observed that during the gas exchange strokes there is generally a small net flow of oil out of the ring pack. During the power strokes this transport process becomes much more important for the oil control ring (and slightly for the second compression ring). Up to $0.135 \mathrm{~cm}^{3} /$ cycle (c.c/cycle) is transported out of the oil control ring during the power stroke compared to the maximum of $0.025 \mathrm{~cm}^{3} / \mathrm{cycle}$ for all other regions. Whilst the persistent net flow down the liner is consistent with the scraping action of the second compression and oil control rings (which tends to return oil towards the sump), the magnitude of this downward scraping action does however appear to diminish with increasing engine load - which presumably reflects the reduced amounts of oil within the ring pack.

It is also clear from Figs. 6 and 7 that the direction of net oil flow is cycle independent for reoions around the oil control ring. In hoth the power and gas 
A study on ring pack lubrication ...

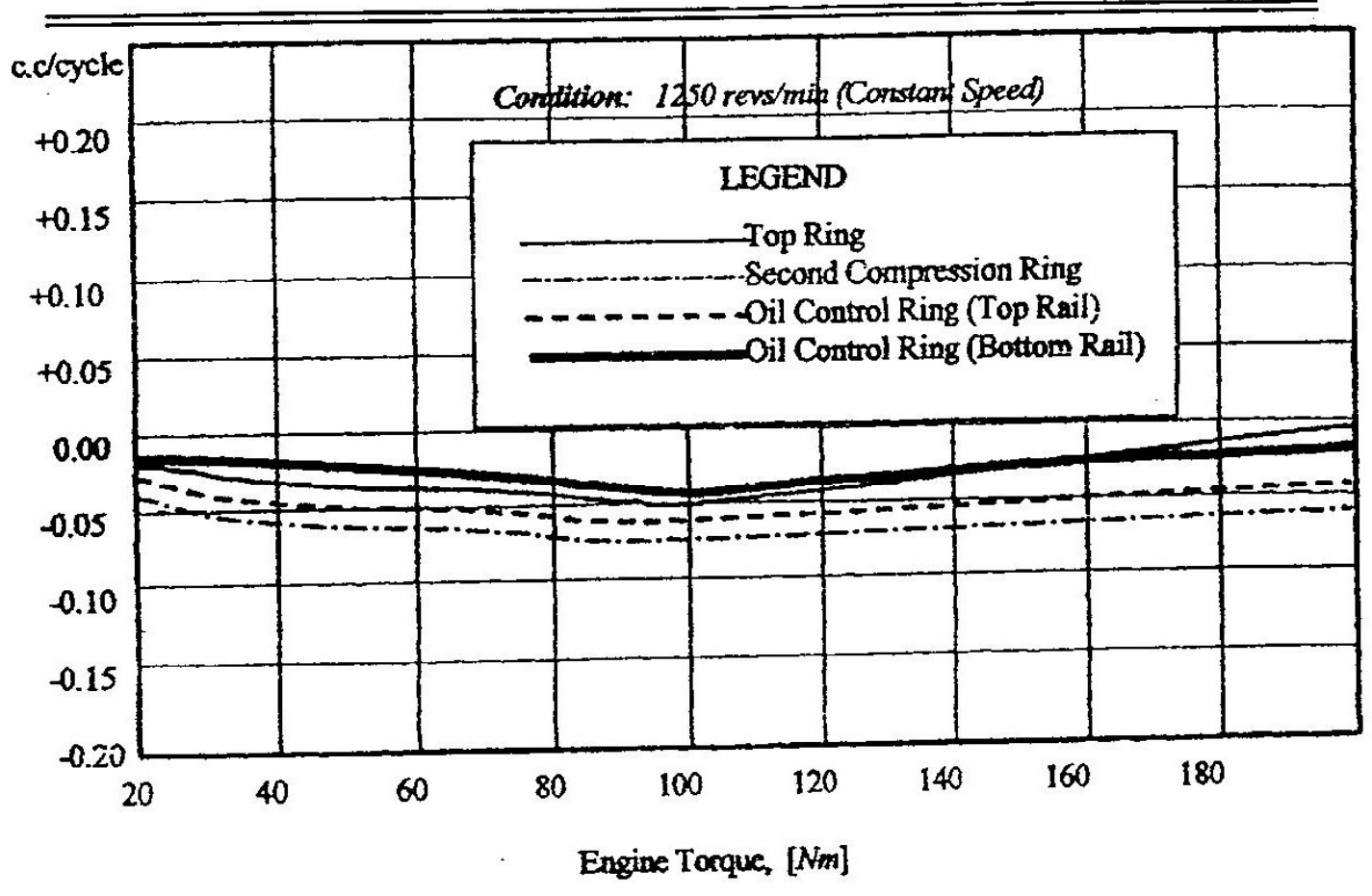

Fig. 7: Net oil flow from individual rings during gas exchange strokes

exchange strokes there is a net oil flcw out of the ring down the liner. This is indicated as negative difference in Fig. 6. In contrast for the upper reaches of the piston i.e. the top ring land and second land regions the direction of net oil flow is cycle dependent. Thus, during the power cycle there is a net flow of lubricant up the liner into the crown and second land regions (positive difference). Whilst during intake there seems to be a small net oil flow of similar magnitude out of these regions down the liner, which is given as a negative difference. This phenomenon suggests that lubricant left behind on the upper reaches of the cylinder wall during the power stroke is scrapped back down the liner during the gas exchange cycle. In principle, oil which is present on the upper portions of the cylinder liner and piston can contribute to the engine's oil consumption depending on how much oil is actually delivered to the combustion chamber in a form which is readily burned. The most likely mechanisms for this probably involve a combination of volatile losses from hot liner and piston surfaces and the transport of oil droplets entrained as a mist into the gas streams within the ring pack.

\section{CONCLUSIONS}

An experimental technique which utilizes laser-induced fluorescence to measure the oil film thickness in the ring pack zone of a four stroke diesel engine has been 


\section{Mshoro}

described. The method has been supplemented by a novel in-situ calibration procedure whereby the fluorescence intensity and oil film thickness were related based on actual engine operating conditions. From the experimental results it has been observed that for a given engine operating condition there are significant cyclic variations in oil film thickness over the ring pack. The largest net oil flows occurred during the power cycle to indicate the dominance of scrapping action of the second compression and oil control rings. Specifically, the compression rings have been observed to be lubricated by a thicker film during expansion and intake strokes than during the compression and exhaust. It has been further observed that oil film thickness under compression rings is virtually unaffected by increasing engine speed and load. On the other hand, lower engine speeds and torque have been observed to yield thicker lubrication films for both rails of the oil control ring, inrespect of the fact that the ring lubrication regime was hydrodynamic. This seems to contradict the widely acceptable theory that under hydrodynamic lubrication the oil film thickness within the ring pack should increase with engine speed. This inconsistency has been explained by the decrease in engine viscosity due to the observed increase in oil temperature within the ring pack as engine speed was increased. The observed behaviour of oil film thickness at low engine torque and speed conditions is probably due to easier transport of lubricant at such conditions, since inherently large amount of oil is normally available for supply to the cylinder liner and for subsequent transport through the ring pack.

This phenomenon has shed some new light in the understanding of ring pack lubrication. If it is indeed that under cold starting and low speed idle conditions thicker oil films are produced in the piston liner region by the lower viscosity lubricant, then, there may be some positive tribological implications, e.g. better protection from cylinder wear, which merits further work. It is however important to note that, in order for any further study with the current method to be more successful, the in-situ calibration procedure developed to relate the fluorescence intensity and oil film thickness need to be improved to enhance efficiency. In the present experiment, it was anticipated that the calibration grooves will be completely filled with oil such that any changes in the flourescence characteristics emitted by the groove sample will be a consequence of changes in the conditions experienced by the oil. This did not happen all the time as their filling was stochastic in nature to call for numerous attempts before any measurements could be made. This exercise was costly and indeed time consuming. 


\section{REFERENCES}

1 Wacker E., Coelingh S., "Analysis of Piston Secondary Motion", Transactions of the Society of Automotive Engineers (SAE), SAE 820131, 1982, pp. 221-229. Behaviour of Reciprocating Slider with Circular Profile", Bulletin of JSME, Vol. 24, No., 194, 1982, pp. 104-113. Parker D.A., Stafford J.V., Kendrick M., Graham N.A., "Experimental Measurements of Piston Cylinder Bore Oil Film Thickness", Proc. of the IMechE Conference on Piston Ring Scuffing, London, Paper C7 1/85, 1985, pp. 22-29. Oh K.P., Li C.H., Goenka P.K., "Elastohydrodynamic Lubrication of Piston Skirts", Journal of Tribology, Vol. 109, (1987) pp. 356-362.

$5 \quad$ Keribar R., Dursunkaya Z., Flemming M.F., "An Integrated Model of Ring Pack Performance", Journal of Power and Gas Turbines, Vol. 113, 1991, pp. 382-389.

6 Goenka P.K., Paranjpe R.S., Jeng Y., "FLARE: An Integrated Software for Friction and Lubrication Analysis of Automotive Engines ", SAE 920487, 1992, pp. 47-55.

7 Keribar R., Dursunikayà Z., Ganapathy V., "An Integrated Design Analysis Methodology to Address Piston Tribological Issues", SAE 930793, 1993, pp. 115-127.

$8 \quad$ Hanks P., "Engine Design Analysis - An Integrated Methodology", Proc. of the Fourth Symposium on Indian Automotive Technology, Pune, Dec. 7-10, 1994, pp. 251-259.

9 Zottin W., Clemente M., Leite J.M.M., "Predictive Analysis of Lube Oil Consumption for a Diesel Engine", SAE 950520 , 1995, pp. 13-18.

10 Sherrington I., Smith E.H., "Experimental Methods for Measuring Oil Film Thickness between Piston and Liner", Tribology International, Vol. 18.6, 1985, pp. 315-320.

11 Grice N., Sherrington I., Smith E.H., O'Donnell S.G., Stringfellow J.F., "A Capacitance Based System for High Resolution Measurement of Oil Film Thicknesses", Proc. of the 4th Nordic Symposium on Tribology and Wear, Hirtshals, June 1990, pp. 349-361. 
Grice N., Sherrington 1., "An Experimental Investigation into the Lubrication of Piston Rings ", SAE 930688, 1993, pp. 3344.

13 Greene A.B., "Initial Visual Studies of Piston-Cylinder Dynamic Oil Film Behaviour", Journal of Wear, Vol. 13, 1969 , pp. 345-351.

14 Ting L.L., "Development of a Laser Fluorescence Technique for Measuring Piston Ring Oil Film Thickness", ASME Journal of Lubrication, Vol. 2, 1979, pp. 67-74.

15 Hoult D.P., Lux J.P., Wong V.W., Billian S.A., "Calibration of Laser Fluorescence Measurements of Lubricant Film Thickness in Engines", SAE 881687, 1988, pp. 89-97.

16 Hoult D.P., Takiguchi M., "Calibration of the Laser Fluorescence Technique Compared with Quantum Theory", ASME Transactions on Tribology, Vol. 34, 1991, pp. 440-449.

17 Wong V.W., Hoult D.P., "Experimental Survey of Lubricant Film Characteristics and Oil Consumption in a Small Diesel Engine", SAE 912388, 1991, pp. 156-166.

18 Cameron A., "Basic Lubrication Theory", Ellis Horwood, Third Edition, 1983.

19 Brown M.A., McCann H., Thompson D.M., "Characterization of Oil Film Behaviour Between the Liner and Piston of a Diesel Engine", SAE 932784, 1993, pp. 135-150.

20 Borman G.L., Richardson D.E., "Using Fibre Optics and Laser Fluorescence for Measuring Oil Films with Applications to Engines", SAE 912388, 1991, pp. 45-57.

21 Burnett P.J., "Relationship Between Oil Consumption, deposit Formation and Piston Ring Motion for Single Cylinder Diesel Engine", SAE 920089, 1992, pp. 1-11. 